\title{
Optimalisasi E-Learning berbasis Virtual Class dengan Google Classroom sebagai Media Pembelajaran Fisika
}

\author{
Erfin Nurfalah
}

\author{
Universitas Islam Negeri Sunan Gunung Djati Bandung \\ email: erfin.nurfalah@gmail.com
}

Received: March 6th 2019. Accepted: June 2nd, 2019. Published: June 29th, 2019

\begin{abstract}
Abstrak
Belakangan ini era revolusi industri 4.0 menjadi perbincangan dunia. Kini dunia tengah menyaksikan perkembangan teknologi di segala sektor, sehingga perkembangan tersebut membawa hal positif bahkan di bidang pendidikan. Akan tetapi hal tersebut juga menjadi tantangan bagi pendidik, salah satunya kemampuan literasi teknologi yang harus dimiliki. Kompetensi abad 21 menuntut agar peserta didik terlibat langsung dalam proses pembelajaran yang memanfaatkan internet. Peserta didik bukan hanya sebatas mencari informasi, tetapi juga melaksanakan pembelajaran secara online. Tujuan penelitian ini adalah mendeskripsikan pembuatan e-learning berbasis virtual class dengan google classroom sebagai media pembelajaran fisika. Metode yang digunakan adalah studi pustaka. Fitur dasar google classroom terdiri atas topik, bahan ajar, pertanyaan, tugas kuis, dan tugas. Pengoptimalan fitur google classroom mempunyai dampak yang penting bagi pembelajaran di era revolusi industri 4.0, antara lain: (1) pembelajaran dilakukan secara online dengan memanfaatkan teknologi, (2) tidak terbatas oleh ruang dan waktu, (3) peserta didik terlibat langsung dalam proses pembelejaran yang memanfaatkan internet, (4) materi pembelajaran mudah diakses, (5) melatih keterampilan literasi data dan literasi teknologi. Google classroom merupakan layanan berbasis internet yang disediakan oleh Google dengan sistem e-learning sehingga dapat dijadikan media pembelajaran yang efisien, efektif serta interaktif untuk menunjang pembelajaran berbasis teknologi.
\end{abstract}


Abstract
Lately, the era of industrial revolution 4.0 has become a global conversation. Now the world is witnessing technological developments in all sectors. So that these developments bring positive things even in the field of education. However, this is also a challenge for educators 4.0, where technological literacy skills must be possessed. 21st century competence requires that students be directly involved in the learning process that utilizes the internet, where students are not only limited to seeking information, but also carry out online learning. The purpose of this research is to describe e-learning based on virtual classes with google classroom as a medium for learning physics. The method used is a literature study. Basic features of google classroom consist of topics, teaching materials, questions, quiz assignments, and assignments. Optimizing the features of google classroom has an important impact on learning in the era of industrial revolution 4.0, including: (1) learning is done online by utilizing technology, (2) not limited by space and time, (3) students are directly involved in the learning process utilizing the internet, (4) learning material that is easy to access, (5) training data literacy skills and technology literacy. Google classroom is an internetbased service provided by Google with an e-learning system. So that it can be used as an efficient, effective and interactive learning media to support technology-based learning. @2019PERJ

Keywords: E-learning, virtual class, google classroom, instructional media. 


\section{PENDAHULUAN}

Pada era digital ini terjadi berbagai disruption, yakni teknologi mengalami perkembangan begitu pesat dengan inovasi-inovasi baru. Hal ini dikarenakan dunia memasuki era revolusi industri 4.0. Teknologi menjadi hal yang paling mendasar pada era tersebut. Perkembangan teknologi informasi dan komunikasi telah memengaruhi beberapa aspek kehidupan manusia, salah satunya di dunia pendidikan. Dampaknya semakin terasa sejalan dengan pergeseran pola pembelajaran tatap muka (konvensional) menuju pendidikan yang lebih terbuka dengan memanfaatkan teknologi informasi dan komunikasi sebagai media pembelajaran (e-learning); serta memenuhi kebutuhan akan informasi yang hampir tidak terbatas.

Indonesia perlu meningkatkan kualitas keterampilan tenaga kerja dengan teknologi digital, termasuk dalam dunia pendidikan (Parray, 2017). Era industri 4.0 menuntut seorang pendidik untuk menjadi pendidik 4.0. Keterampilan abad 21 harus dimiliki serta berbagai macam teknologi sudah seharusnya diterapkan dalam pengajaran di kelas (Yustanti \& Novita, 2019). Kompetensi abad 21 menuntut agar peserta didik terlibat langsung dalam proses pembelajaran yang memanfaatkan internet. Peserta didik bukan hanya sebatas mencari informasi, tetapi juga melaksanakan pembelajaran secara online (Sohibun \& Ade, 2017).

Seorang pendidik 4.0 perlu merencanakan berbagai macam teknik pembelajaran yang kreatif dan inovatif berbasis teknologi. Elearning merupakan salah satu wujud perkembangan teknologi informasi di dunia pendidikan. Pengembangan teknologi ini dapat dimanfaatkan secara maksimal oleh peserta didik dalam proses pembelajaran, terutama dalam penerapan pembelajaran berbasis masalah. Literasi teknologi saat ini dapat dilihat dengan munculnya blanded learning sebagai bagian dari proses pembelajaran. Blanded learning merupakan penggabungan antara pembelajaran tatap muka dan pemanfaatan sumber daya jaringan internet sebagai suplemen pembelajaran (Rahmad, Wirda, \& Berutu, 2019).

Materi pelajaran dari berbagai sumber yang mudah diakses akan membantu pendidik dalam merencanakan dan menerapkan pembelajaran di dalam kelas. Penerapan pembelajaran dengan mengkolaborasikan pembelajaran tatap muka dengan pembelajaran jarak jauh dapat meningkatkan waktu belajar peserta didik. Terlebih pada mata pelajaran fisika yang sering dianggap sulit oleh peserta didik yang mengakibatkan minimnya rasa suka terhadap mata pelajaran fisika. Permasalahan 
tersbut dapat diatasi melalui penggunaan e-learning berbasis virtual class dengan google classroom.

Google classroom adalah layanan berbasis internet yang disediakan oleh Google sebagai sebuah sistem e-learning berbasis virtual class sebagai bentuk pembelajaran jarak jauh yang dilakukan melalui media internet secara virtual di dunia maya (Hakim, 2016). Google classroom mampu mengatasi keterbatasan ruang dan waktu serta memudahkan pendidik untuk mengevaluasi setiap kegiatan yang telah dilakukan oleh peserta didik. Selain itu, google classroom juga dapat membantu dalam kegiatan pemantauan untuk memecahkan masalah dan membuat pembelajaran lebih efektif dan efisien.

Pembelajaran kolaboratif antara tatap muka dengan jarak jauh (elearning berbasis virtual class) dengan google classroom menjadi lebih bermakna karena materi pembelajaran yang disediakan dirancang sedemikian rupa sehingga peserta didik lebih mudah memahaminya. Selain itu, materi bisa di ulang-ulang ketika ada materi yang kurang dipahami sehingga dapat meningkatkan hasil belajar peserta didik.

\section{METODE}

Metode penelitian yang digunakan adalah studi pustaka.
Pengumpulan data dilakukan dengan mencari dan mengumpulkan informasi yang berhubungan dengan e-learning, virtual class, dan google classroom. Informasi yang diperoleh dianalisis dan literatur-literatur yang berhubungan dengan pendidikan dikaji lebih mendalam, serta dilakukan survey lapangan untuk melihat efektivitas pemanfaatan $e$ learning berbasis virtual class, dan google classroom.

\section{HASIL DAN PEMBAHASAN}

Berdasarkan hasil studi pustaka, dapat dirangkum bahwa penggunaan media pembelajaran dengan e-learning berbasis virtual class menggunakan google classroom memberikan kemudahan kepada pengguna untuk mendapatkan banyak materi dari internet. Pembelajaran berbasis virtual membuat kegiatan berlangsung secara interaktif antara pendidik dan peserta didik.

Penggunaan google clasroom tidak perlu melakukan proses instalasi yang rumit. Setelah seorang administrator melakukan setup account Google, pendidik dan peserta didik bisa menggunakan google classroom dengan akun email Google masing-masing. Kelas virtual dapat dibuat dengan google classroom. Tahapan yang dilakukan adalah masuk ke setup account Google terlebih dahulu, kemudian klik Google apps $\rightarrow$ Classroom. 
Tampilan laman Google pada langkah awal pembuatan google classroom dapat dilihat pada Gambar 1.

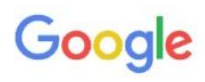

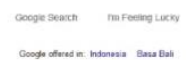

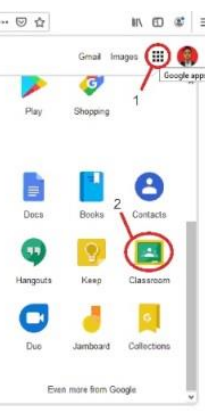

Gambar 1. Tampilan Laman Google pada Langkah Awal Pembuatan Google Classroom

Setelah meng Klik "Classroom", langkah selanjutnya yaitu klik menu $(+) \rightarrow$ lalu buat kelas seperti pada Gambar 2.

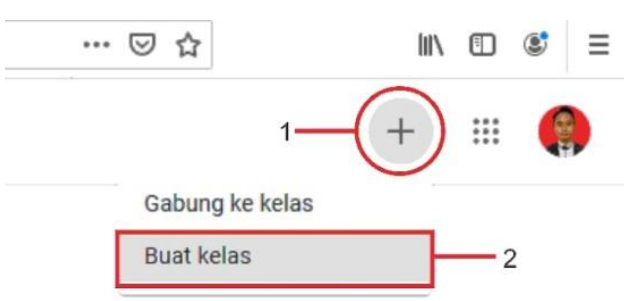

Gambar 2. Langkah Pembuatan Google Classroom

Setelah meng Klik "Buat kelas" maka akan muncul kotak dialog sebelum menggunakan kelas. Pada kotak dialog terdapat kotak kecilyang harus dicentang, kemudian klik lanjutkan. Setelah itu akan muncul tampilan seperti Gambar 3. Isi form sesuai kebutuhan, kemudian klik "buat" untuk melanjutkan.

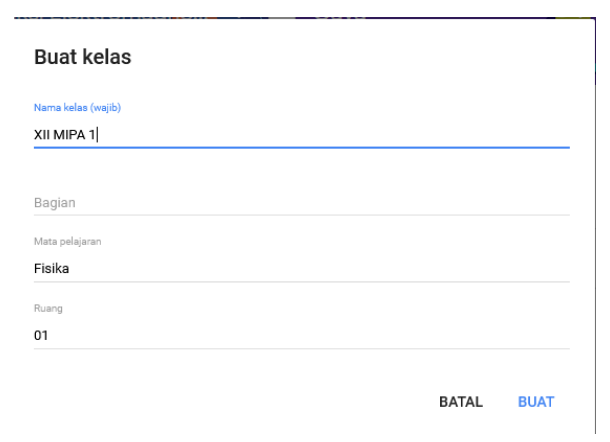

Gambar 3. Tampilan Laman pada Langkah Pembuatan Google Classroom

Setelah dibuat maka akan muncul halaman baru yang berisi fitur google classroom seperti Gambar 4.

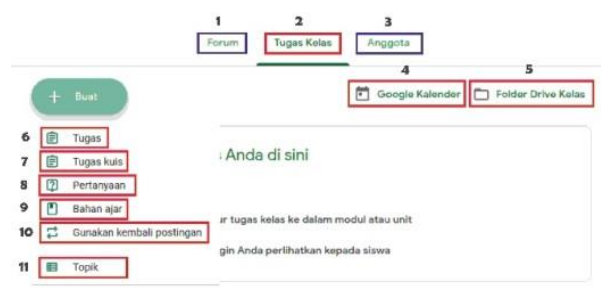

Gambar 4. Tampilan Fitur Google Classroom

Keterangan dari Gambar 4 adalah sebagai berikut:

1. Forum

Fitur ini merupakan tempat interaksi antara pendidik dan peserta didik. Ketika pendidik membagikan bahan ajar, tugas, maupun pertanyaan maka akan muncul pemberitahuan di forum tersebut; seperti yang ditunjukkan pada Gambar 5 . 


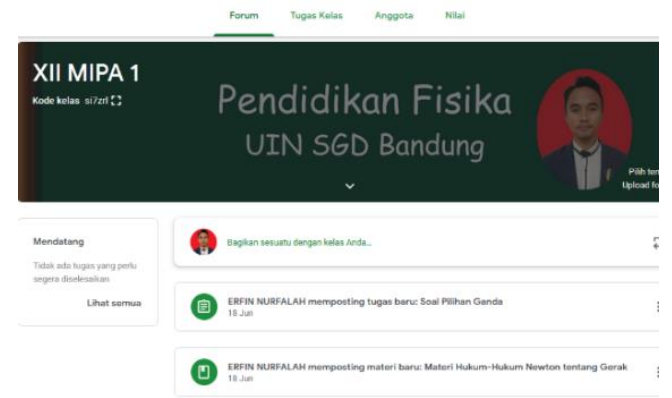

Gambar 5. Tampilan pada Fitur Forum

2. Tugas Kelas

Fitur ini merupakan tempat bagi pendidik untuk membuat tugas.

3. Anggota

Pada fitur ini, pemilik akun dapat melihat jumlah anggota termasuk pendidik dan peserta didik, dan pendidik juga dapat menambahkan anggota peserta didik dengan memasukkan username e-mail peserta didik.

4. Google Kalender

Pendidik dapat membuat schedule time pada fitur ini.

5. Folder Drive Kelas

File-file yang sudah diupload akan tersimpan dalam google drive.

6. Tugas

Fitur ini untuk membagikan tugas, baik berupa Microsoft Word, Power Point, atau media lainnya.

7. Tugas Kuis

Pendidik dapat membuat kuis dengan bantuan google form, baik berupa pilihan ganda maupun uraian. Selain itu, fitur ini juga disertai dengan informasi batas waktu; sehingga ketika peserta didik sudah mengerjakan tugas, maka sistem akan mencatat waktu pengumpulan tugas oleh peserta didik dan pendidik bisa melihat status pengumpulan tugas peserta didik, terlambat atau tepat waktu. Selanjutnya, pendidik bisa memberikan penilaian terhadap tugas yang dikerjakan oleh peserta didik.

8. Pertanyaan

Pendidik dapat membuat pertanyaan secara online dan masing-masing peserta didik dapat memberikan jawaban terhadap pertanyaan tersebut.

9. Bahan Ajar

Pada fitur ini, pendidik dapat membagikan bahan ajar baik berupa Microsoft word, Power Point, video, maupun media lainnya. Tampilan fitur bahan ajar dapat dilihat pada Gambar 6.

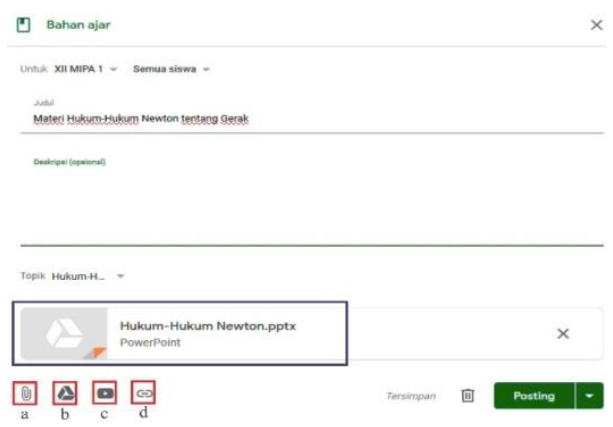

Gambar 6. Fitur Bahan Ajar 
Langkah-langkah mengupload materi pada fitur bahan ajar diuraikan sebagai berikut:.

1) Isi terlebih dahulu judul, kemudian pilih topik (bahasan) sesuai dengan materi.

2) Isi bahan ajar dengan beberapa fitur seperti yang ditunjukkan pada Gambar 6 yang diberi kotak berwarna merah.

Berikut penjelasannya:

a) Fitur untuk mengupload file pada peragkat anda (komputer/laptop/smart -phone), dapat berupa Microsoft Word, Power Point, atau media lainnya.

b) Fitur ini untuk menambahkan file yang sudah terupload di google drive.

c) Pada fitur ini, pengguna dapat menyisipkan video dari youtube dengan cara menyalin url youtube.

d) Fitur ini merupakan tempat untuk menyalin link dari berbagai sumber/referensi.

3) Setelah selesai, maka akan muncul tampilan seperti yang di tunjukkan pada Gambar 6 yang diberi kotak berwarna biru, kemudian klik "posting".
10. Gunakan Kembali Postingan Fitur ini untuk merepost kembali postingan yang sudah diupload.

11. Topik

Berupa pokok bahasan sesuai materi yang di ajarkan.

Sistem pelaksanaan ujian nasional kini sudah menggunakan CBT (Computer Based Test) yang jenis soalnya pilihan ganda. Oleh karena itu, peserta didik perlu dilatih agar terbiasa dengan soalsoal berbasis komputer. Hal ini juga dapat diterapkan pada ulangan harian, Ujian Tengah Semester, bahkan Ujian Akhir Semester.

Langkah pembuatan kuis jenis pilihan ganda pada google classroom antara lain: membuat tugas kuis yang dapat dilihat pada Gambar 4, kemudian akan muncul tampilan seperti pada Gambar 7; selanjutnya klik "Blank Quiz" untuk membuat kuis.

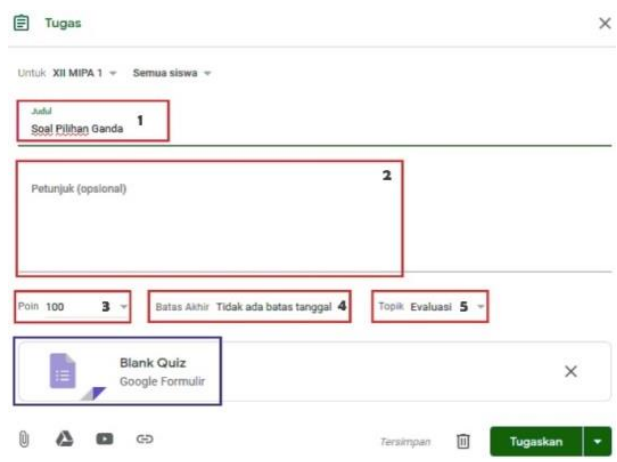

Gambar 7. Langkah Pembuatan Kuis Pilihan Ganda pada Google Classroom 
Keterangan dari Gambar 7 adalah sebagai berikut:

a) Judul kuis

b) Deskripsi dari kuis

c) Total poin yang akan diberikan

d) Jangka waktu pelaksanaan kuis

e) Topik

Google Classroom menyediakan menu untuk membuat pertanyaan dengan tipe soal pilihan ganda sebagai berikut:

1. Tambahkan pertanyaan

Digunakan untuk menulis dan menambah pertanyaan.

2. Impor pertanyaan

Digunakan untuk menambah pertanyaan yang sudah terupload melalui google.

3. Tambahkan judul dan deskripsi.

4. Tambahkan gambar

Digunakan untuk menyisipkan gambar dalam pertanyaan.

5. Tambahkan video

Menu ini dapat digunakan untuk menambah video yang langsung terhubung dengan link youtube.

6. Tambahkan bagian

Digunakan untuk menambah bagian ke dua untuk membuat pertanyaan.

7. Poin

Masing-masing poin yang akan diberikan pada tiap soal diatur pada menu ini.

8. Pratinjau

Digunakan untuk melihat kuis yang sudah dibuat.
Tampilan laman tipe soal pilihan ganda bisa dilihat pada Gambar 8 .

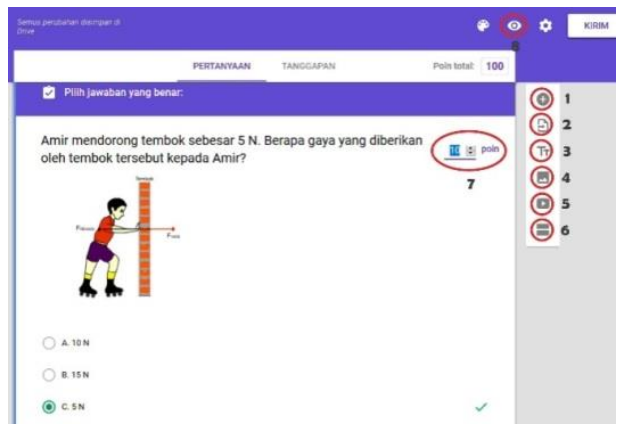

Gambar 8. Tampilan Laman Tipe Soal Pilihan Ganda

Pendidik dapat membuat pertanyaan secara online dan masing-masing peserta didik dapat memberikan jawaban terhadap pertanyaan tersebut untuk membuat kelas menjadi lebih interaktif.

Google classroom adalah Sistem Manajemen Pembelajaran yang di tawarkan oleh Google untuk pendidik. Aplikasi ini menyediakan lokasi sentral untuk berkomunikasi dengan peserta didik, mengajukan pertanyaan, dan membuat tugas (Sudarsana, Putra, Astawa, \& Yogantara, 2019). google classroom membantu memfasilitasi pembelajaran online untuk peserta didik abad 21 ini. Selain itu, google classroom memiliki potensi untuk menghemat sebagian besar waktu bagi peserta didik dan pendidik karena proses menyiapkan google classroom sangat cepat dan nyaman untuk digunakan. Waktu tidak akan 
terbuang sia-sia untuk mendistribusikan dokumen fisik karena tugas yang telah diberikan kepada peserta didik oleh pendidik dapat diselesaikan tepat waktu secara online. Hal tersebut membuat kendala waktu yang kurang ketika pembelajaran tatap muka berlangsung dapat teratasi.

Pendidikan di Indonesia kini telah berbasis komputer dalam evaluasi belajar tahap akhir (Ujian Nasional). Ujian masuk perguran tinggi juga sekarang sudah menggunakan sistem CBT (Computer Based Test) sehingga pengoptimalan kelas virtual dengan google classroom sangat berguna agar peserta didik terbiasa dengan soal-soal berbasis komputer.

Penggunaan aplikasi google classroom juga dapat mengasah kemampuan literasi data dan literasi teknologi peserta didik. Hal tersebut disebabkan peserta didik terlibat langsung dalam proses pembelajaran yang memanfaatkan internet sehingga pembelajaran menjadi lebih bermakna. Selain itu, pendidik 4.0 memerlukan open growth mindset, yakni cara berpikir yang mengembang dan terbuka (Kasali, 2018). Cara berpikir tersebut diperlukan agar pembelajaran yang akan diberikan kepada peserta didik menjadi lebih kreatif, inovatif dan menarik.

\section{KESIMPULAN}

Pengoptimalan fitur google classroom mempunyai dampak penting bagi pembelajaran di era revolusi industri 4.0, antara lain: (1) pembelajaran dilakukan secara online dengan memanfaatkan teknologi, (2) tidak terbatas oleh ruang dan waktu, (3) peserta didik terlibat langsung dalam proses pembelajaran yang memanfaatkan internet, (4) materi pembelajaran mudah di akses, (5) melatih keterampilan literasi data dan literasi teknologi. Pembuatan google classroom dapat dilakukan secara mudah oleh pendidik untuk membuat pembelajaran menjadi efektif dan efisien.

\section{REFERENSI}

Fitriningtiyas, Umamah, \& Sumardi. 2019. Google classroom: As a Media of Learning History. Journal of Physics .

Hakim, A. B. 2016. Efektifitas Penggunaan E-Learning Moodle, Google Classroom dan Edmodo. STIMIK ESQ

Kasali, R. 2018. Disruption. Jakarta: PT Gramedia Pustaka Utama.

Parray. 2017. Indonesia Jobs Outlook 2017 Harnessing Technology For Growth and Job Creation. Jakarta: International Labour Office.

Rahmad, R., Wirda, M. A., \& Berutu, N. 2019. Google Classroom Implementation In Indonesian 
Higher Education. Journal of Physics.

Sohibun, \& Ade, F. Y. 2017. Pengembangan Media Pembelajaran Berbasis Virtual Class Berbantuan Google Drive. Tadris: Jurnal Kependidikan dan Ilmu Tarbiyah.

Sudarsana, K., Putra, M. A., Astawa,

N. T., \& Yogantara, W. L.
2019. The Use of Google Classroom in The Learning Process. Journal of Physics .

Yustanti, I., \& Novita, D. 2019. Pemanfaatan E-Learning Bagi Para Pendidik Di Era Digital 4.0. Prosiding Seminar Nasional Pendidikan Program Pascasarjana Universitas PGRI Palembang . 